\title{
Regio and stereoselectivity in ionic cycloadditions ${ }^{\dagger}$
}

\author{
VENKATACHALAM TAMILMANI, DURAIRAJAN SENTHILNATHAN and \\ PONNAMBALAM VENUVANALINGAM*
}

School of Chemistry, Bharathidasan University, Tiruchirappalli 620024

e-mail: venuvanalingam $@$ yahoo.com

MS received 17 July 2007; accepted 27 December 2007

\begin{abstract}
Acridizinium cation (ACR) and 2,3-dimethylisoquinolinium ion (DMIQ) undergo $\left[2+4^{+}\right]$ addition with dienophiles methyl vinyl ether (MVE) and propylene (PY) and the addition takes place across the diene unit containing the cationic centre and the dienophile acts as the electron donor. These reactions have two regiochemical paths and in each of them two possible stereo adducts could be formed. DFT calculations performed at B3LYP/6-31G(d) level have shown that the reactions pass through concerted mechanism and the TSs are highly asynchronous. Methoxy group in the dienophile can take up cis or trans orientation with respect to the double bond and in that trans orientation of the methoxy group is preferred. Calculations further show that syn 2 adduct is kinetically and thermodynamically more favoured in both the reactions in excellent agreement with the experimental observations. ACR is found to be more reactive than DMIQ as a diene and as a dienophile MVE is found to be more reactive than PY. Computed bond orders establish that the syn 2 transition states are the most 'reactant' like. Though the reactions have both electrostatic control and frontier orbital control the former dominates in the initial stages of the reaction.
\end{abstract}

Keywords. Stereoselectivity; ionic cycloaddition; density functional theory; acridizinium ion; methyl vinyl ether; 2,3-dimethylisoquinolinium ion.

\section{Introduction}

In polar or ionic cycloadditions both or either of the addends is ionic, and they can be either a cation or anion but anionic cycloadditions are very rare. When both the addends are neutral partners, the reaction generally prefers concerted mechanism and introduction of electronegative atoms like, oxygen, nitrogen in the reaction site induces asynchronicity in the transition states. In dipolar or ionic cycloadditions mechanistic cross over from concerted to step-wise path has been observed. ${ }^{1}$ The effect of heteroatom substitution in ionic addends could have a different effect and have not been investigated before, specifically in terms of mechanism and this has been the main motivation for this work. In ionic cycloadditions, in addition to frontier orbital control, electrostatic control could have a significant influence and affect the course of the reaction. Further cationic addends have a low-lying LUMO and anionic

\footnotetext{
${ }^{\dagger}$ Presented in the Theoretical Chemistry Symposium 2006 held during 11-13 December 2006 in Tiruchirappalli, India *For correspondence
}

addends have a high-lying HOMO and this enhances the reactivity of these addends towards addition. This reaction principle has been used in the synthesis of many carbocycles, heterocycles, less reactive $\pi$ systems and heteromultiple bonds. ${ }^{2}$ ACR and DMIQ have been specifically chosen here as they have been reported to undergo 1,4 as cycloadditions with some dienophiles. ${ }^{3-10}$ Bradsher and co-workers have shown that ACR undergoes $\left[2+4^{+}\right]$DA reaction with MVE and PY to give stereoselective isomer which is $s y n$ to the phenylene ring ${ }^{8-10}$ with the methoxy/methyl substituent maximally displaced from ring nitrogen. Further, they have investigated the reaction of DMIQ with $\mathrm{CP}^{6}$ and $\mathrm{MVE}^{4,7}$ for the understanding of high regio and stereoselectivity. In the ionic cycloaddition of ACR, stereoselectivity, ${ }^{5}$ peri strain ${ }^{6}$ and electrostatic repulsion ${ }^{7}$ play an important role. We have modelled DMIQ-CP reaction and analysed the role of electrostatic control on this reaction. ${ }^{11}$ In the case of DMIQ reaction with MVE, $97 \%$ of stereoselective adduct has the methoxyl group directed over the phenylene moiety (syn 2 ). These interesting observations have also stimulated us to explore mechanism of the ACR/DMIQ reactions with MVE/ PY, inves- 


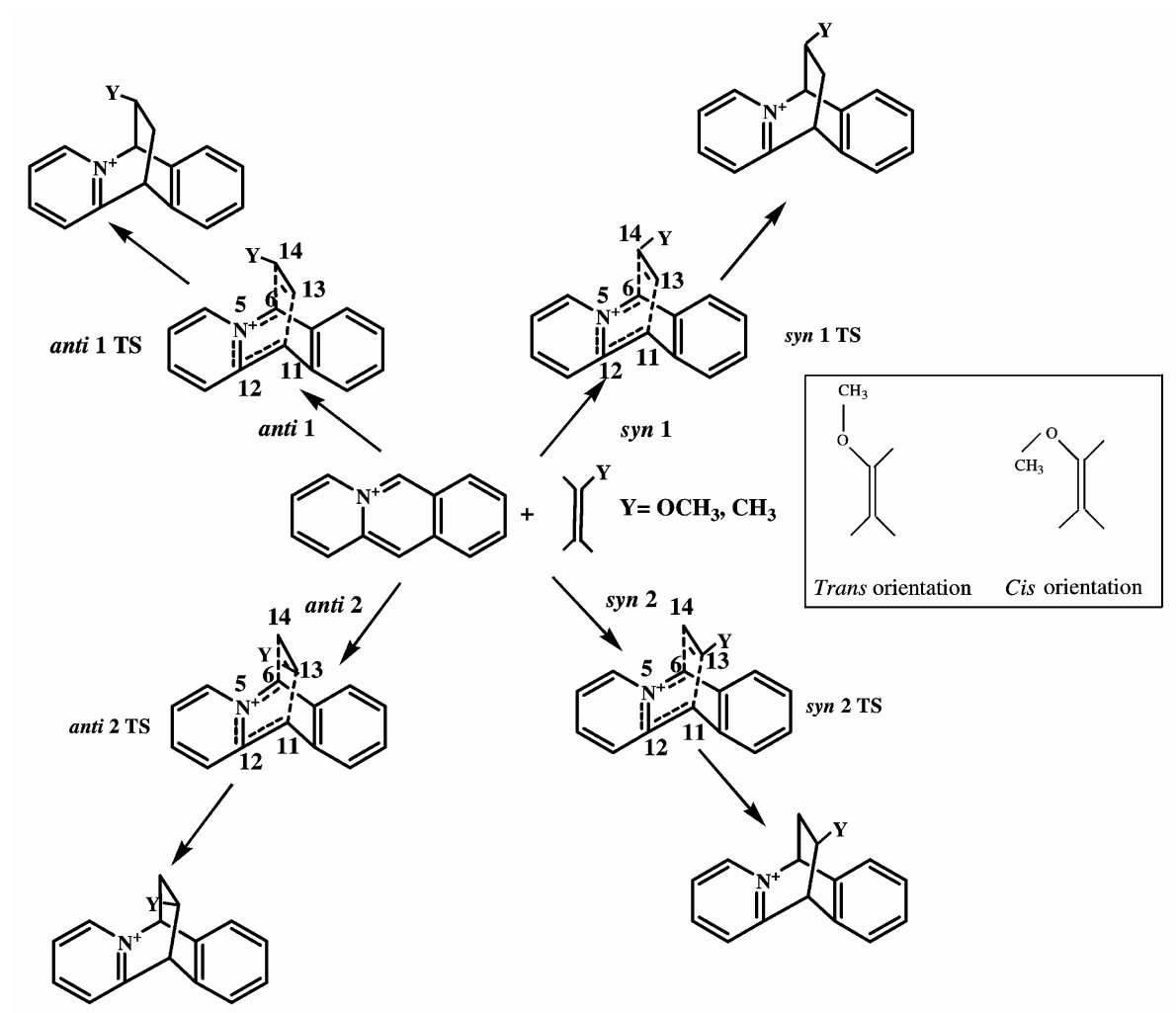

Scheme 1. Possible reaction pathways for the $\left[2+4^{+}\right]$reaction between PY, MVE and ACRs. Trans and cis orientations of MVE is given in the inset.
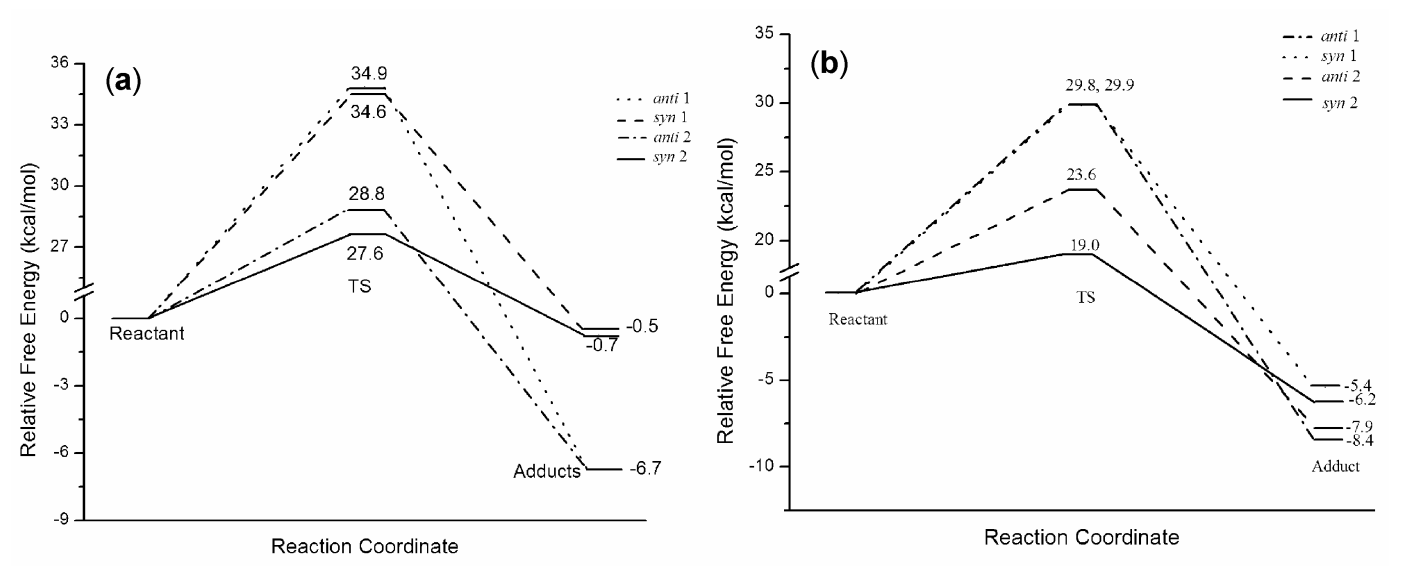

Figure 1. Free energy profile for the $\left[2+4^{+}\right]$reaction of ACR with MVE (a) cis orientation, (b) trans orientation.

tigate further the factors that influence the reaction pathway and its regio and stereoselectivity.

\section{Computational details}

Density functional theory (DFT) calculations have been performed using B3LYP method with 6-31G(d) basis set. The optimizations were carried out using the Berny ${ }^{12}$ analytical gradient optimization method. Stationary points have been located and characterized by computing the vibrational frequencies for reactants, products and transition states. In all cases, reactants and products had all real frequencies and the transition states had a single imaginary frequency. 

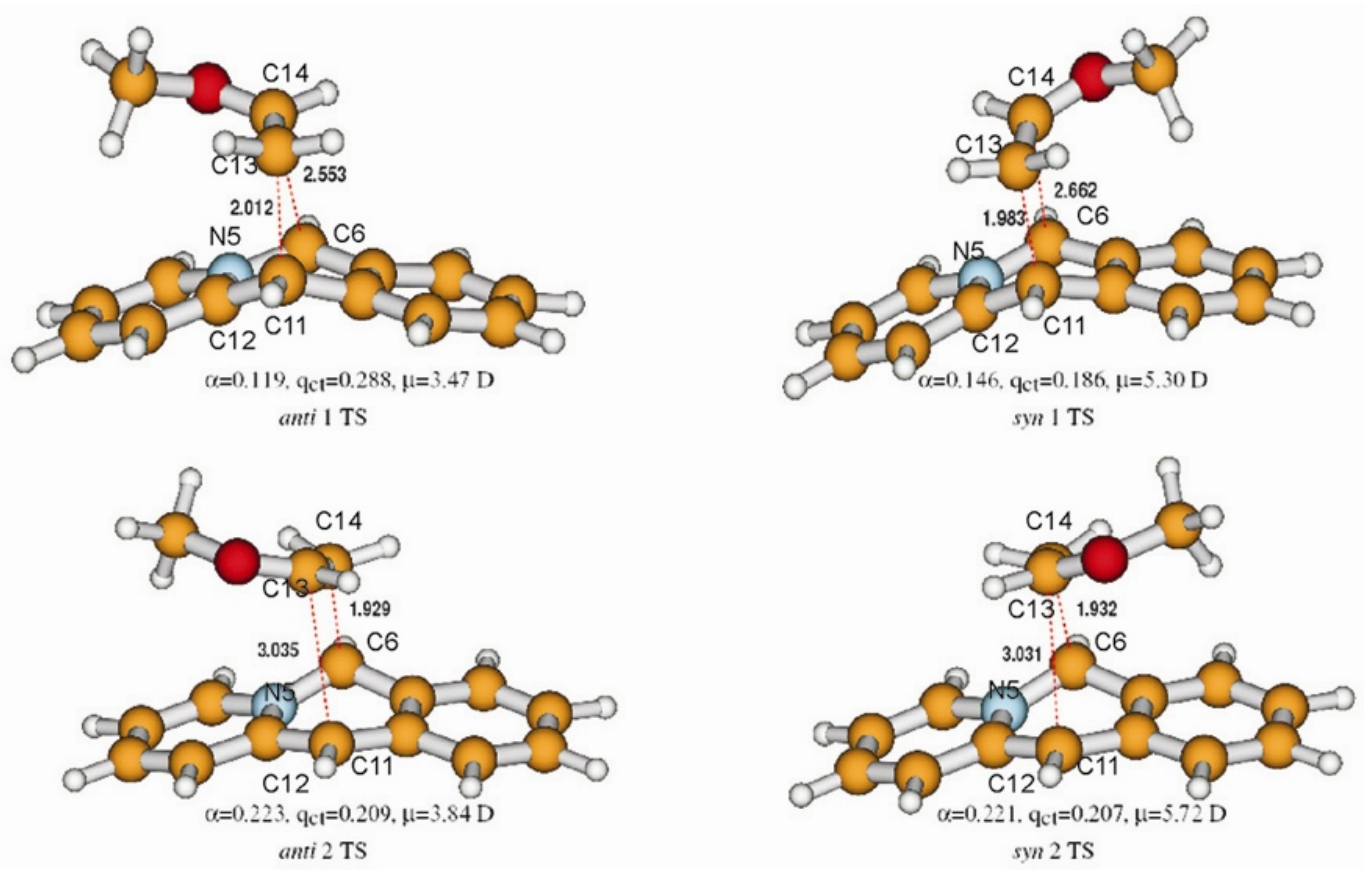

(a) cis orientation
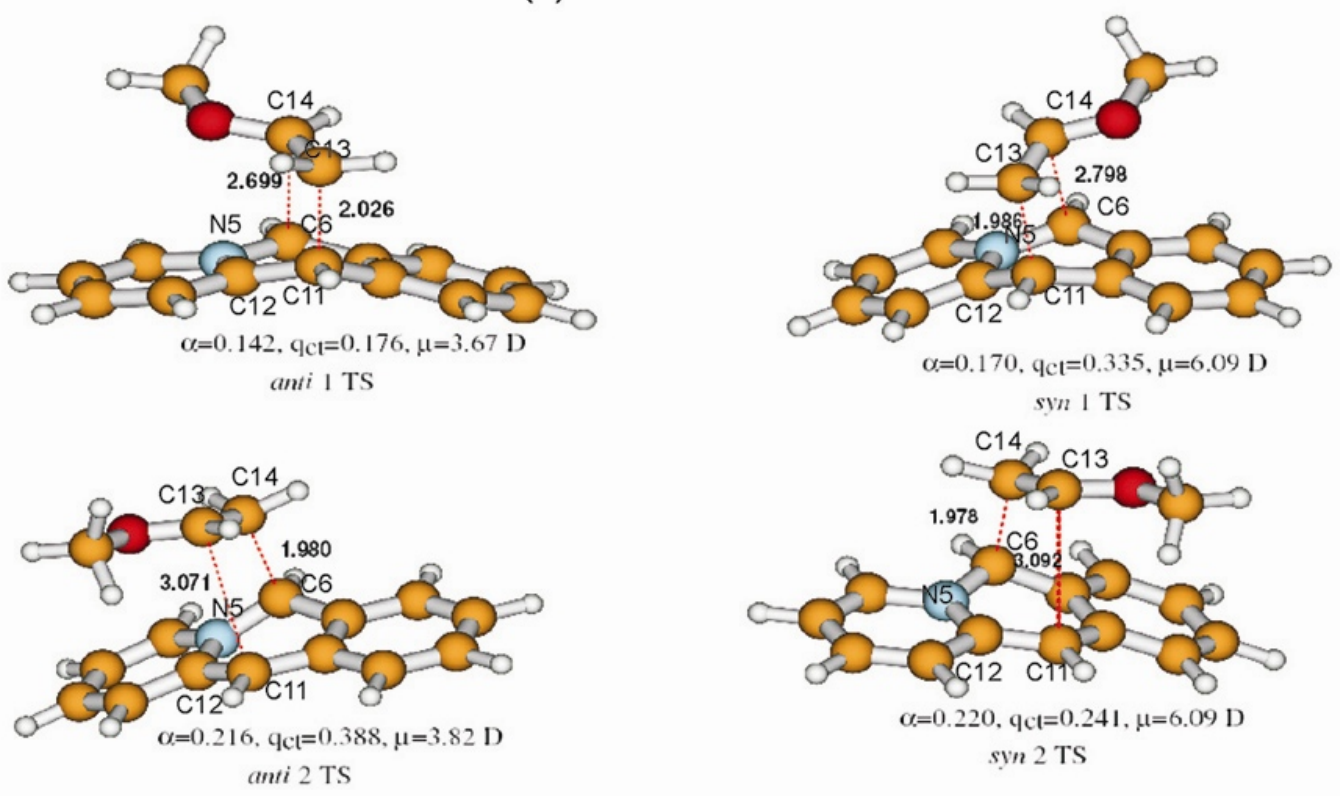

(b) trans orientation

Figure 2. Optimized transition state geometries for the $\left[2+4^{+}\right]$reaction between MVE (trans orientation) and ACR along with degree of asynchronicity $(\alpha)$, quantum of charge transfer $\left(q_{c t}\right)$ and dipole moment $(\mu)$.

Transition states have been further confirmed by animating the imaginary frequency in MOLDEN. The intrinsic reaction coordinate (IRC) paths were traced to check the energy profiles connecting each transition structure to the two associated minima of the proposed mechanism by using the second-order
Gonzalez-Schlegel integration method. ${ }^{13,14}$ Free energy and enthalpy calculations have been done using thermochemical calculations. All computations have been carried out using Gaussian 03, Revision B.01 and C. $01 .{ }^{15}$ Bond orders have been calculated from the Wiberg ${ }^{16}$ indices using NBO analysis and from 
Table 1. Thermochemical parameters for the reaction of ACR with MVE and PY $\left(\Delta G^{\ddagger}, \Delta H^{\ddagger}\right.$, $\Delta G_{r}, \Delta H_{r}$ are in $\mathrm{kcal} / \mathrm{mol}$ and $\Delta S^{\dagger}, \Delta S_{r}$ in $\left.\mathrm{cal} / \mathrm{mol} / \mathrm{K}\right)$ and frontier orbital energy gap values $(\mathrm{eV})$.

\begin{tabular}{|c|c|c|c|c|c|c|c|c|}
\hline Addition & $\Delta G^{+}$ & $\Delta H^{+}$ & $\Delta S^{+}$ & $\Delta G_{r}$ & $\Delta H_{r}$ & $\Delta S_{r}$ & $\Delta E_{1}$ & $\Delta E_{2}$ \\
\hline \multicolumn{9}{|l|}{ MVE-ACR reaction } \\
\hline $\begin{array}{l}\text { Cis orientation } \\
\text { anti } 1 \\
\text { syn } 1 \\
\text { anti } 2 \\
\text { syn } 2\end{array}$ & $\begin{array}{l}34 \cdot 9 \\
34 \cdot 6 \\
28 \cdot 8 \\
27 \cdot 6\end{array}$ & $\begin{array}{l}21.7 \\
21.4 \\
15 \cdot 6 \\
14.7\end{array}$ & $\begin{array}{l}-44 \cdot 3 \\
-44 \cdot 3 \\
-44 \cdot 3 \\
-43 \cdot 3\end{array}$ & $\begin{array}{l}-6 \cdot 7 \\
-0.5 \\
-6 \cdot 7 \\
-0.7\end{array}$ & $\begin{array}{l}-21 \cdot 1 \\
-13.7 \\
-15.6 \\
-13.5\end{array}$ & $\begin{array}{l}-48 \cdot 3 \\
-44 \cdot 2 \\
-29 \cdot 9 \\
-43 \cdot 0\end{array}$ & $8 \cdot 63$ & $0 \cdot 18$ \\
\hline $\begin{array}{l}\text { Trans orientation } \\
\text { anti } 1 \\
\text { syn } 1 \\
\text { anti } 2 \\
\text { syn } 2\end{array}$ & $\begin{array}{l}29.8 \\
29.9 \\
23.6 \\
19.0\end{array}$ & $\begin{array}{l}17 \cdot 4 \\
17 \cdot 6 \\
11 \cdot 5 \\
10 \cdot 6\end{array}$ & $\begin{array}{l}-41 \cdot 6 \\
-41 \cdot 3 \\
-40 \cdot 6 \\
-28 \cdot 2\end{array}$ & $\begin{array}{l}-8 \cdot 4 \\
-5 \cdot 4 \\
-7 \cdot 9 \\
-6 \cdot 2\end{array}$ & $\begin{array}{l}-21 \cdot 8 \\
-19 \cdot 2 \\
-21 \cdot 8 \\
-20 \cdot 0\end{array}$ & $\begin{array}{l}-45 \cdot 0 \\
-46 \cdot 3 \\
-46 \cdot 6 \\
-46 \cdot 3\end{array}$ & 8.78 & $0 \cdot 38$ \\
\hline $\begin{array}{l}\text { PY-ACR reaction } \\
\text { anti } 1 \\
\text { syn } 1 \\
\text { anti } 2 \\
\text { syn } 2\end{array}$ & $\begin{array}{l}34 \cdot 7 \\
34 \cdot 3 \\
32 \cdot 3 \\
31 \cdot 8\end{array}$ & $\begin{array}{l}21 \cdot 0 \\
20 \cdot 8 \\
19 \cdot 0 \\
18 \cdot 6\end{array}$ & $\begin{array}{l}-46 \cdot 0 \\
-45 \cdot 3 \\
-44 \cdot 6 \\
-44 \cdot 3\end{array}$ & $\begin{array}{l}-7 \cdot 4 \\
-7 \cdot 7 \\
-7 \cdot 4 \\
-7 \cdot 5\end{array}$ & $\begin{array}{l}-22 \cdot 3 \\
-22 \cdot 6 \\
-22 \cdot 3 \\
-22 \cdot 4\end{array}$ & $\begin{array}{l}-50 \cdot 0 \\
-50 \cdot 0 \\
-50 \cdot 0 \\
-50 \cdot 0\end{array}$ & $9 \cdot 07$ & 0.50 \\
\hline
\end{tabular}

Table 2. Percentage of bond formation $\left(B F_{i}\right)$ and cleavage $\left(B C_{j}\right)$ of selected bonds in the TSs for the reaction of ACR with MVE and PY.

\begin{tabular}{|c|c|c|c|c|c|c|c|c|c|}
\hline \multirow[b]{2}{*}{ Species } & \multicolumn{3}{|c|}{$B F_{i}$} & \multicolumn{3}{|c|}{$B C_{i}$} & \multirow[b]{2}{*}{$\mathrm{BF}_{\mathrm{Ave}}$} & \multirow[b]{2}{*}{$\mathrm{BF}_{\mathrm{Ave}}$} & \multirow[b]{2}{*}{$\mathrm{BFC}_{\mathrm{Ave}}$} \\
\hline & $\mathrm{N}_{5}-\mathrm{C}_{12}$ & $\mathrm{C}_{11}-\mathrm{C}_{13}$ & $\mathrm{C}_{14}-\mathrm{C}_{6}$ & $\mathrm{C}_{6}-\mathrm{N}_{5}$ & $\mathrm{C}_{12}-\mathrm{C}_{11}$ & $\mathrm{C}_{13}-\mathrm{C}_{14}$ & & & \\
\hline \multicolumn{10}{|c|}{ MVE-ACR reaction } \\
\hline \multicolumn{10}{|c|}{ Cis orientation } \\
\hline anti $1 \mathrm{TS}$ & $29 \cdot 60$ & $52 \cdot 84$ & $23 \cdot 90$ & $24 \cdot 27$ & $50 \cdot 84$ & $55 \cdot 98$ & $35 \cdot 45$ & $43 \cdot 70$ & $39 \cdot 58$ \\
\hline syn $1 \mathrm{TS}$ & $32 \cdot 34$ & $54 \cdot 96$ & $21 \cdot 37$ & $23 \cdot 34$ & $54 \cdot 95$ & $57 \cdot 88$ & $36 \cdot 39$ & $45 \cdot 39$ & $40 \cdot 89$ \\
\hline anti $2 \mathrm{TS}$ & $4 \cdot 57$ & $12 \cdot 10$ & $57 \cdot 80$ & $46 \cdot 18$ & $19 \cdot 78$ & $59 \cdot 04$ & $24 \cdot 82$ & $41 \cdot 67$ & $33 \cdot 25$ \\
\hline syn $2 \mathrm{TS}$ & 0.41 & $12 \cdot 22$ & $57 \cdot 06$ & $45 \cdot 92$ & $18 \cdot 07$ & $58 \cdot 28$ & $23 \cdot 23$ & $40 \cdot 76$ & $32 \cdot 00$ \\
\hline \multicolumn{10}{|c|}{ Trans orientation } \\
\hline anti $1 \mathrm{TS}$ & $30 \cdot 20$ & $50 \cdot 26$ & $20 \cdot 65$ & $22 \cdot 77$ & $50 \cdot 84$ & $53 \cdot 61$ & $33 \cdot 70$ & $41 \cdot 76$ & $37 \cdot 73$ \\
\hline syn $1 \mathrm{TS}$ & $32 \cdot 80$ & $53 \cdot 33$ & $18 \cdot 46$ & $23 \cdot 05$ & $54 \cdot 20$ & $56 \cdot 04$ & $34 \cdot 86$ & $44 \cdot 43$ & $39 \cdot 65$ \\
\hline anti $2 \mathrm{TS}$ & $1 \cdot 39$ & $11 \cdot 83$ & $52 \cdot 40$ & $42 \cdot 19$ & $15 \cdot 83$ & $54 \cdot 19$ & $21 \cdot 87$ & $37 \cdot 40$ & $29 \cdot 64$ \\
\hline syn $2 \mathrm{TS}$ & $1 \cdot 43$ & $10 \cdot 99$ & $52 \cdot 23$ & $42 \cdot 79$ & $16 \cdot 97$ & $54 \cdot 33$ & $21 \cdot 55$ & $38 \cdot 03$ & $29 \cdot 79$ \\
\hline \multicolumn{10}{|c|}{ PY-ACR reaction } \\
\hline anti $1 \mathrm{TS}$ & $33 \cdot 26$ & $33 \cdot 28$ & $38 \cdot 33$ & $37 \cdot 38$ & $25 \cdot 52$ & $48 \cdot 57$ & $34 \cdot 96$ & $37 \cdot 16$ & $36 \cdot 06$ \\
\hline syn $1 \mathrm{TS}$ & $35 \cdot 57$ & $32 \cdot 60$ & $39 \cdot 05$ & $39 \cdot 68$ & $26 \cdot 11$ & $48 \cdot 66$ & $35 \cdot 74$ & $38 \cdot 15$ & $36 \cdot 95$ \\
\hline anti $2 \mathrm{TS}$ & $19 \cdot 56$ & $22 \cdot 20$ & $48 \cdot 52$ & $43 \cdot 18$ & $3 \cdot 67$ & $50 \cdot 67$ & $30 \cdot 09$ & $32 \cdot 51$ & $31 \cdot 30$ \\
\hline syn $2 \mathrm{TS}$ & $20 \cdot 96$ & $21 \cdot 69$ & $48 \cdot 78$ & $44 \cdot 27$ & $5 \cdot 27$ & $51 \cdot 06$ & $30 \cdot 48$ & $33 \cdot 54$ & $32 \cdot 01$ \\
\hline
\end{tabular}

them bond formation index $\mathrm{BF}_{\mathrm{i}}$ and bond cleavage index $\mathrm{BC}_{\mathrm{j}}$ have been calculated as described by Manoharan and Venuvanalingam. ${ }^{17-19}$

\section{Results and discussion}

\subsection{Acridizinium ion as a diene}

The detailed mechanistic scheme for the $\left[2+4^{+}\right]$addition of MVE with ACR is given in scheme 1 and free energy profile is presented in figure 1 . The optimized geometries are depicted in figure 2. Computed thermodynamic data and FOE gap values $(\mathrm{eV})$ are presented in table 1. Bond order analysis data for the reaction of ACR with MVE and PY are given in table 2. ACR has three diene units and therefore, in principle, the cycloaddition can undergo across any of these units but $\mathrm{C} 6-\mathrm{N} 5-\mathrm{C} 11-\mathrm{C} 12$ unit forms the LUMO and therefore the reaction undergoes prefer- 


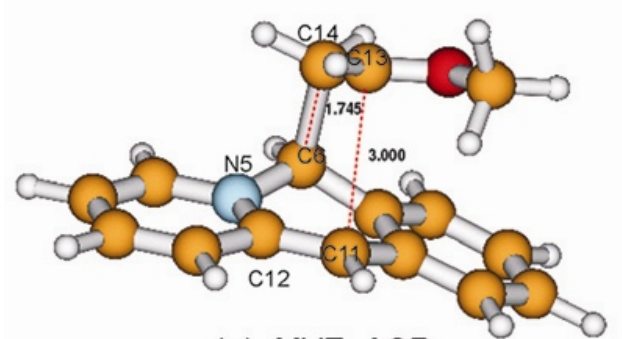

(a) MVE-ACR

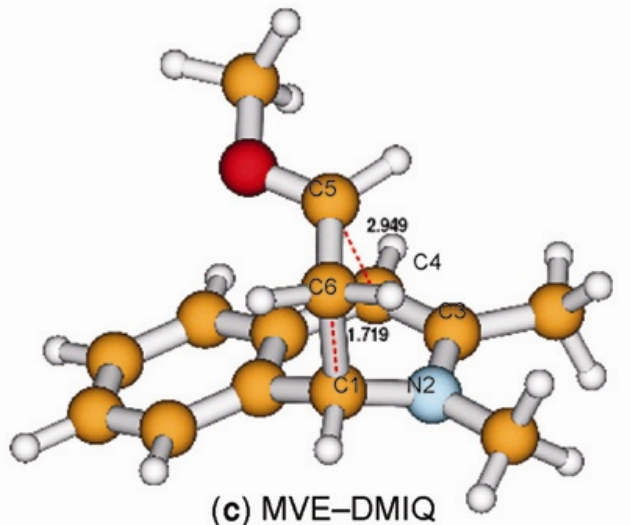

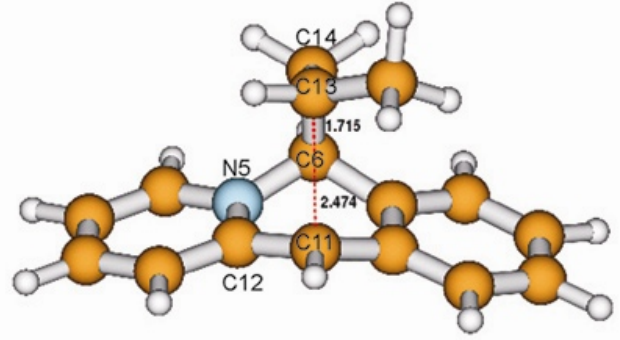

(b) PY-ACR

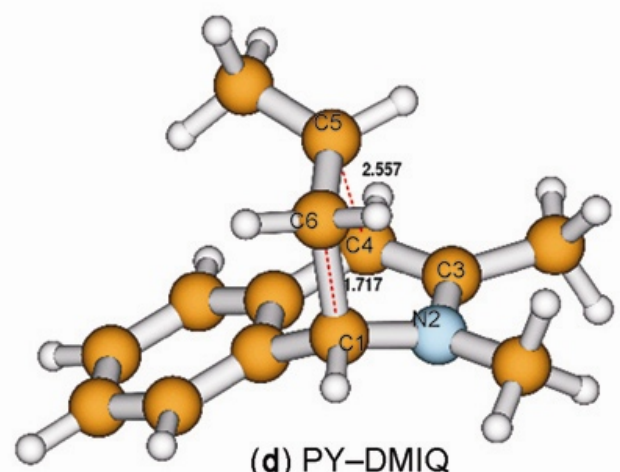

(d) PY-DMIQ

Figure 3. Structures of the species which lie at 'half way' between the TS and product: Pathways for the $\left[2+4^{+}\right]$DA reactions.
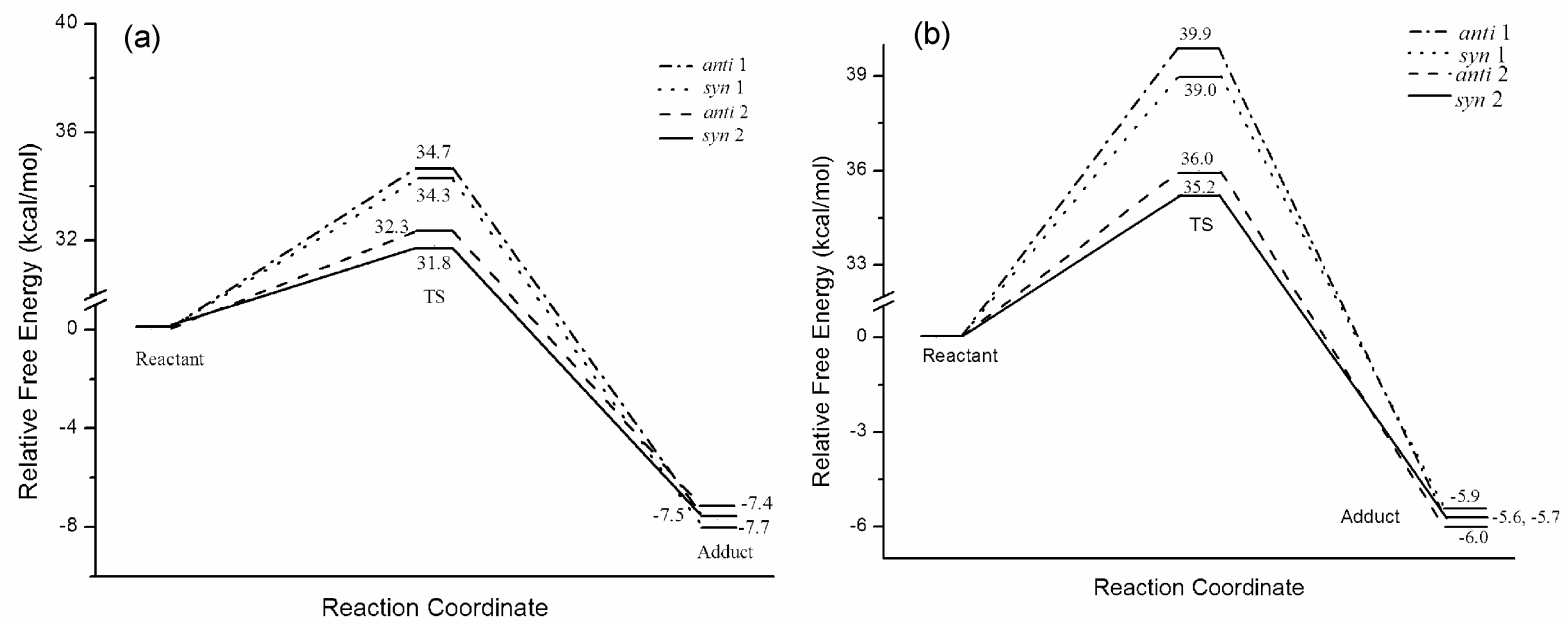

Figure 4. Free energy profile for the $\left[2+4^{+}\right]$reaction between (a) PY-ACR and (b) PY-DMIQ.

entially across this unit. Therefore, pathways involving other two units have not been considered for any further discussion as they are not preferred.

3.1a Reaction between acridizinium ion and methyl vinyl ether: Computed FOE gap values (table 1) show that this is an inverse electron demand type reaction and this is due to the fact that the diene is a cation and has a very low-lying LUMO and the calculated $q_{c t}$ (figure 2) values indicate the transfer of charge from dienophile to diene. Scheme 1 shows that four pathways are open for this reaction and they are described as syn 1, anti 1, syn 2 and anti 2 depending on methoxy group orientation with respect to the phenylene ring and its disposition towards C6 atoms. Regio 1 path will have two stereo adducts syn 1 and anti 1 and regio 2 path will have two stereo adducts syn 2 and anti 2. Further, the 
Table 3. Thermochemical parameters for the reaction of DMIQ with MVE and PY $\left(\Delta G^{\ddagger}\right.$, $\Delta H^{\dagger}, \Delta \mathrm{G}_{\mathrm{r}}, \Delta H_{\mathrm{r}}$ are in $\mathrm{kcal} / \mathrm{mol}$ and $\Delta S^{\dagger}, \Delta S_{r}$ in $\left.\mathrm{cal} / \mathrm{mol} / \mathrm{K}\right)$ and frontier orbital energy gap values $(\mathrm{eV})$.

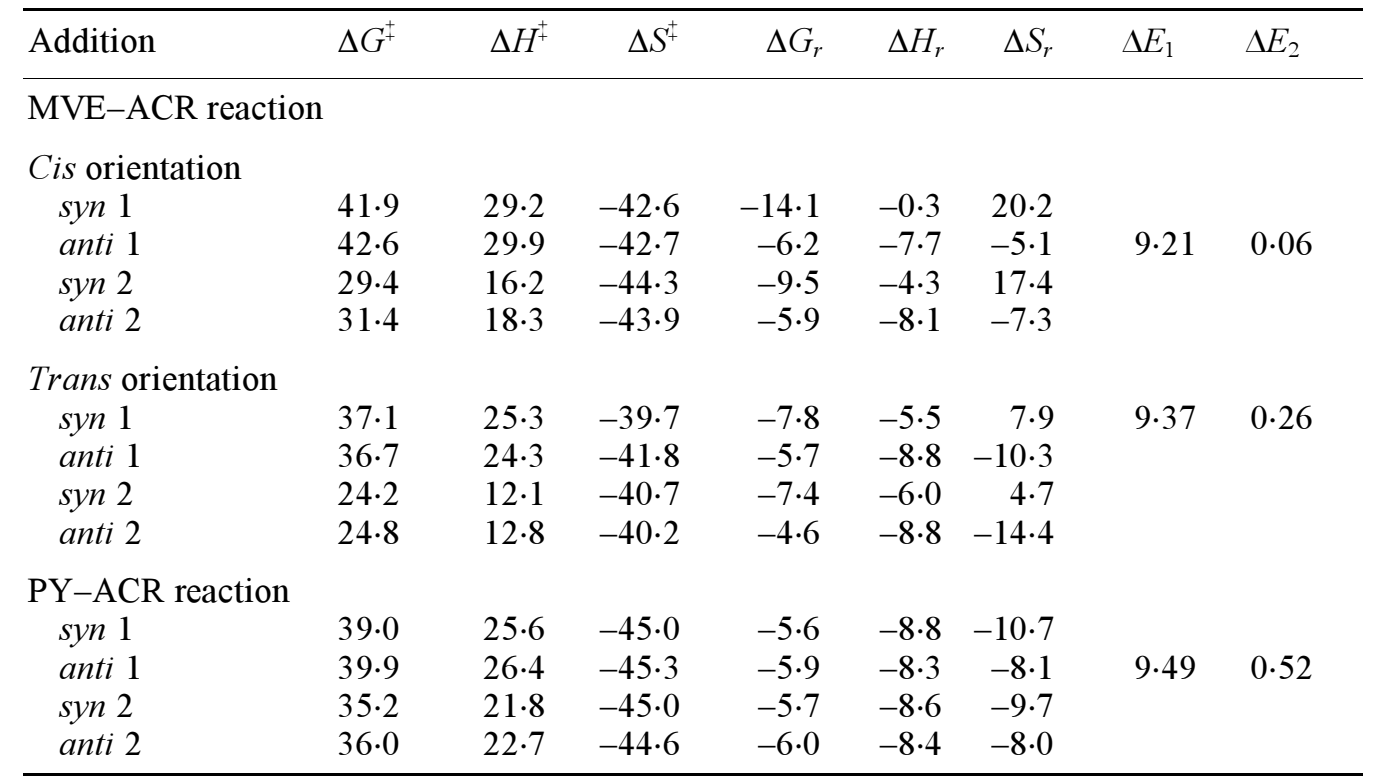

$\Delta E_{1 \text { Hомо }}$ (diene)- $\mathrm{E}_{\mathrm{LUMO}}$ (dienophile). $\Delta E_{2 \text { Hомо }}$ (dienophile) $-E_{\mathrm{LUMO}}$ (diene)

Table 4. Percentage of bond formation $\left(B F_{i}\right)$ and cleavage $\left(B C_{j}\right)$ of selected bonds in the TSs for the reaction of DMIQ with MVE and PY.

\begin{tabular}{|c|c|c|c|c|c|c|c|c|c|}
\hline \multirow[b]{2}{*}{ Species } & \multicolumn{3}{|c|}{$B F_{i}$} & \multicolumn{3}{|c|}{$B C_{i}$} & \multirow[b]{2}{*}{$\mathrm{BF}_{\mathrm{Ave}}$} & \multirow[b]{2}{*}{$\mathrm{BF}_{\mathrm{Ave}}$} & \multirow[b]{2}{*}{$\mathrm{BFC}_{\mathrm{Ave}}$} \\
\hline & $\mathrm{N}_{2}-\mathrm{C}_{3}$ & $\mathrm{C}_{6}-\mathrm{C}_{1}$ & $\mathrm{C}_{5}-\mathrm{C}_{4}$ & $\mathrm{C}_{1}-\mathrm{N}_{2}$ & $\mathrm{C}_{3}-\mathrm{C}_{11}$ & $\mathrm{C}_{5}-\mathrm{C}_{6}$ & & & \\
\hline \multicolumn{10}{|c|}{ MVE-ACR reaction } \\
\hline \multicolumn{10}{|c|}{ Cis orientation } \\
\hline syn $1 \mathrm{TS}$ & $43 \cdot 18$ & $57 \cdot 82$ & $30 \cdot 17$ & $40 \cdot 01$ & $62 \cdot 20$ & $61 \cdot 47$ & $43 \cdot 69$ & $54 \cdot 56$ & $49 \cdot 13$ \\
\hline anti $1 \mathrm{TS}$ & $40 \cdot 65$ & $52 \cdot 18$ & $29 \cdot 83$ & $40 \cdot 81$ & $55 \cdot 51$ & $54 \cdot 91$ & $40 \cdot 88$ & $50 \cdot 41$ & $45 \cdot 65$ \\
\hline syn $2 \mathrm{TS}$ & $5 \cdot 62$ & $11 \cdot 28$ & $67 \cdot 00$ & $56 \cdot 65$ & $0 \cdot 00$ & $65 \cdot 83$ & $27 \cdot 96$ & $40 \cdot 82$ & $34 \cdot 39$ \\
\hline anti $2 \mathrm{TS}$ & $4 \cdot 62$ & $11 \cdot 16$ & $65 \cdot 77$ & $55 \cdot 50$ & $0 \cdot 00$ & $64 \cdot 36$ & $27 \cdot 18$ & $36 \cdot 99$ & $32 \cdot 09$ \\
\hline \multicolumn{10}{|c|}{ Trans orientation } \\
\hline syn $1 \mathrm{TS}$ & $42 \cdot 55$ & $59 \cdot 32$ & $25 \cdot 03$ & $38 \cdot 54$ & $64 \cdot 52$ & $60 \cdot 95$ & $42 \cdot 30$ & $54 \cdot 67$ & $48 \cdot 48$ \\
\hline anti $1 \mathrm{TS}$ & $41 \cdot 17$ & $52 \cdot 32$ & $30 \cdot 39$ & $41 \cdot 26$ & $56 \cdot 02$ & $56 \cdot 69$ & $41 \cdot 29$ & $51 \cdot 32$ & $46 \cdot 30$ \\
\hline syn $2 \mathrm{TS}$ & $6 \cdot 41$ & $10 \cdot 36$ & $61 \cdot 06$ & $53 \cdot 05$ & 0.63 & $61 \cdot 49$ & $25 \cdot 94$ & $38 \cdot 39$ & $32 \cdot 16$ \\
\hline anti $2 \mathrm{TS}$ & $46 \cdot 36$ & $11 \cdot 26$ & $61 \cdot 56$ & $52 \cdot 30$ & $2 \cdot 17$ & $61 \cdot 37$ & $39 \cdot 73$ & $38 \cdot 61$ & $39 \cdot 17$ \\
\hline \multicolumn{10}{|c|}{$\mathrm{PY}-\mathrm{ACR}$ reaction } \\
\hline syn 1 TS & $31 \cdot 57$ & $31 \cdot 30$ & $49 \cdot 31$ & $50 \cdot 56$ & $33 \cdot 99$ & $54 \cdot 14$ & $37 \cdot 39$ & $46 \cdot 23$ & $41 \cdot 81$ \\
\hline anti $1 \mathrm{TS}$ & $31 \cdot 59$ & $31 \cdot 91$ & $48 \cdot 65$ & $49 \cdot 20$ & $33 \cdot 37$ & 53.74 & $37 \cdot 38$ & $45 \cdot 44$ & $41 \cdot 41$ \\
\hline syn $2 \mathrm{TS}$ & $19 \cdot 60$ & $21 \cdot 03$ & $58 \cdot 42$ & $54 \cdot 13$ & $18 \cdot 39$ & $57 \cdot 92$ & $33 \cdot 02$ & $43 \cdot 48$ & $38 \cdot 25$ \\
\hline anti $2 \mathrm{TS}$ & $19 \cdot 95$ & $21 \cdot 53$ & $57 \cdot 52$ & $52 \cdot 65$ & $19 \cdot 26$ & $57 \cdot 31$ & $33 \cdot 00$ & $43 \cdot 07$ & $38 \cdot 04$ \\
\hline
\end{tabular}

methoxy group in dienophile can take up two orientations, cis or trans with respect to the double bond as shown in (inset) scheme 1. Then, there are eight stereo adducts possible for this reaction. Both concerted and step-wise paths for all these stereoselective additions have been attempted but concerted paths alone could be located and all the transition structures are found to be asynchronous as reflected in the $\alpha^{20}$ values (figure 1) and this is in view of asymmetry in the structure of diene and dienophile. In all these eight possible paths $\mathrm{C} 6-\mathrm{C} 13$ bond is found to be shorter than $\mathrm{C} 11-\mathrm{C} 14$ in the concerted TS and this gives clear evidence that in the beginning phase of the reaction electrostatic control is dominant. C6 

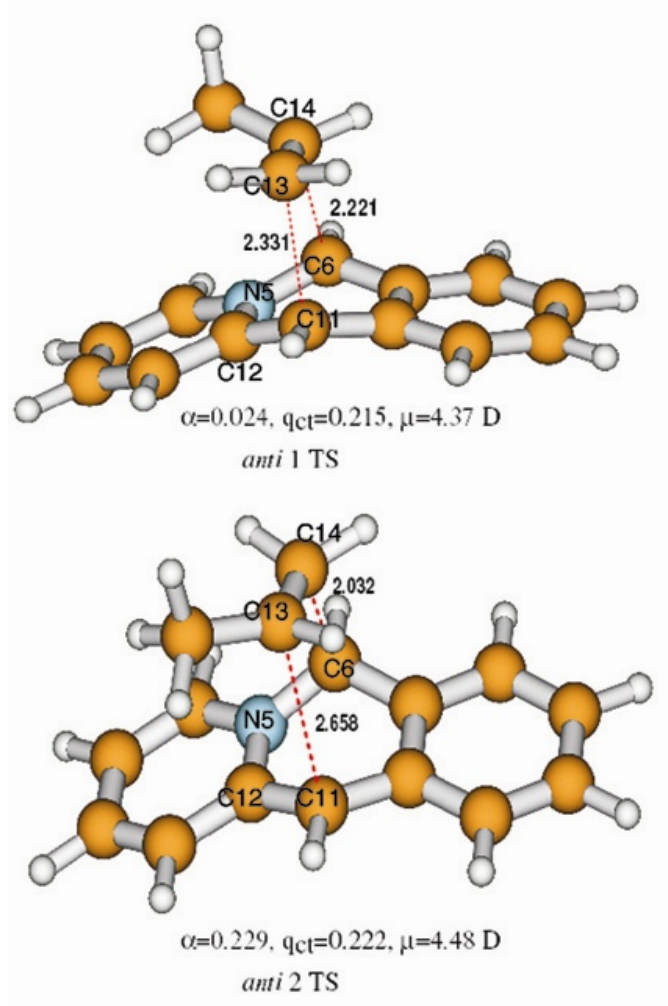
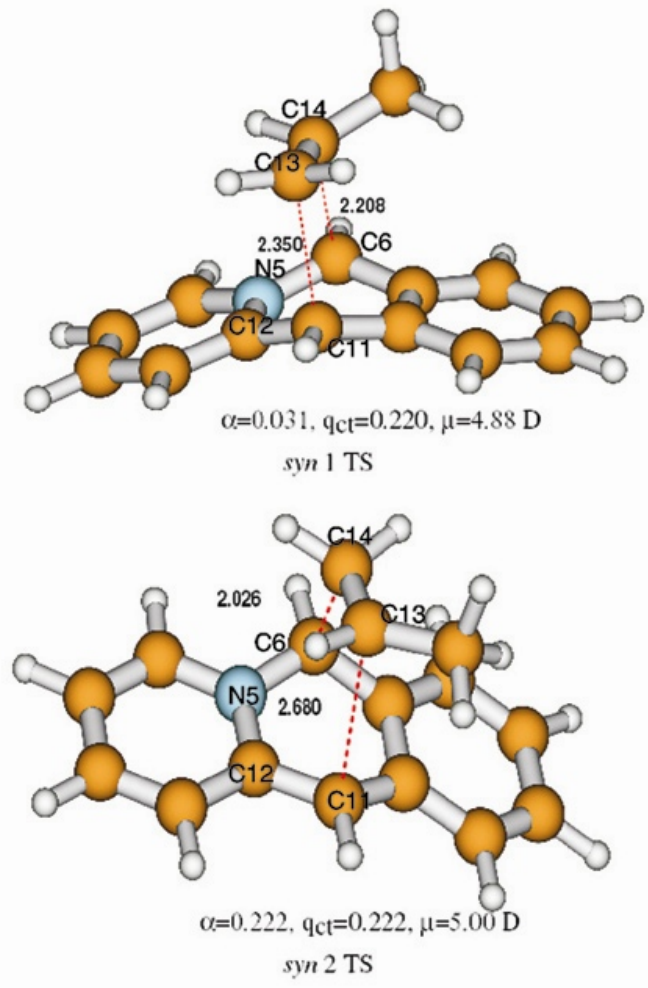

Figure 5. Optimized transition state geometries for the $\left[2+4^{+}\right]$reaction between PY and ACR along with degree of asynchronicity $(\alpha)$, quantum of charge transfer $\left(q_{c t}\right)$ and dipole moment $(\mu)$.

is more electropositive and interacts strongly with the negative end of the dienophile and forms the bond quickly over the other forming bond $\mathrm{C} 11-\mathrm{C} 14$. The latter bond develops at a slower pace and this leads to asynchronous TSs. The computed free energies of activation data presented in table 1 show that the trans orientation is more favoured compared to cis orientation by approximately $5 \mathrm{kcal} / \mathrm{mol}$. So, further discussions are restricted to trans adducts.

The free energy of activation for the anti 1, syn 1, anti 2 and syn 2 reactions are found to be 29.8, 29.9, 23.6 and $19.0 \mathrm{kcal} / \mathrm{mol}$ respectively and this clearly indicates that syn 2 adduct is the most favoured one from kinetic considerations. Computed enthalpy of activation of syn 2 is $10.6 \mathrm{kcal} / \mathrm{mol}$ and on comparison with all the adducts entropy loss is found to be less in syn 2. This is in good agreement with the report of Bradsher and co-workers. ${ }^{8}$ IRC calculations are found to connect the reactant and the corresponding products. When newly forming bonds mature at different rates asynchronous structure forms but this has to be carefully distinguished from TSs leading to step-wise intermediates. This can be done by moving the TS 'forward' along intrinsic reaction coordinate (IRC). If the weaker bond starts growing in the forward direction the TS is concerted asynchronous and if the second bond does not mature it is a step-wise TS. This can be verified by examining the bond length of newly forming bonds in halfway structures. By 'halfway' structures it is meant that species that lie on the reaction path originating from TS and ending at the product. There is a gradual increase in the formation of $\mathrm{C} 11-\mathrm{C} 14$ bond on moving the reaction system from the TS towards the products and this confirms that the TSs are concerted. TSs and the corresponding structure of the species which lie at 'half way' between the TS and the product are shown in figure 3(a). The possibility of step-wise mechanism is thus ruled out. Bond order analysis shows the bond formation and cleavage indices and their average. $\mathrm{BFC}_{\mathrm{Ave}}$ gives the average percentage of all main bond forming and cleaving processes at various species. Lower $\mathrm{BFC}_{\mathrm{Ave}}$ value, that are less than 50, indicate 'early' or 'reactant' like or 'loose' nature of the TS and higher values indicate 'late' or 'product' like or 'tight' nature of the TS. This is the 
<smiles>[Y]C1CC2c3ccccc3C([N+](C)=O)C1C2C</smiles>

syn 1 TS

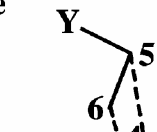<smiles>CCCCC</smiles>

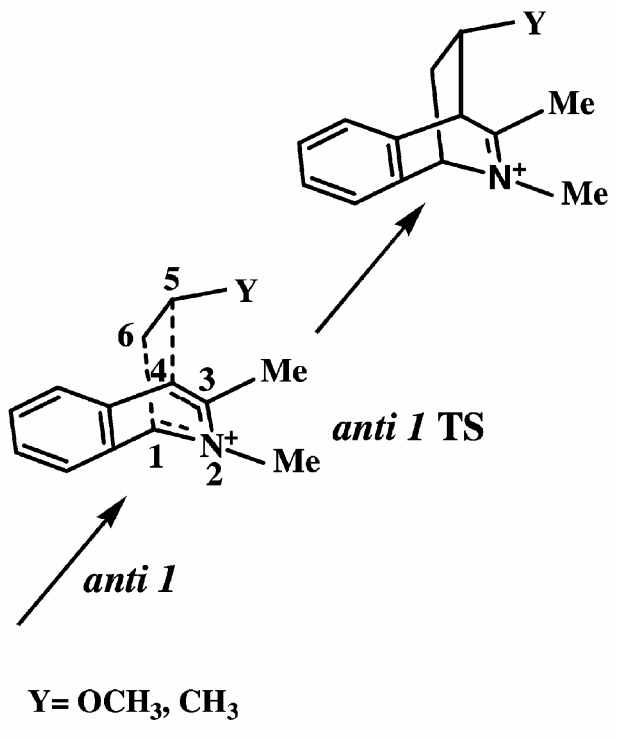

$\searrow$ anti 2

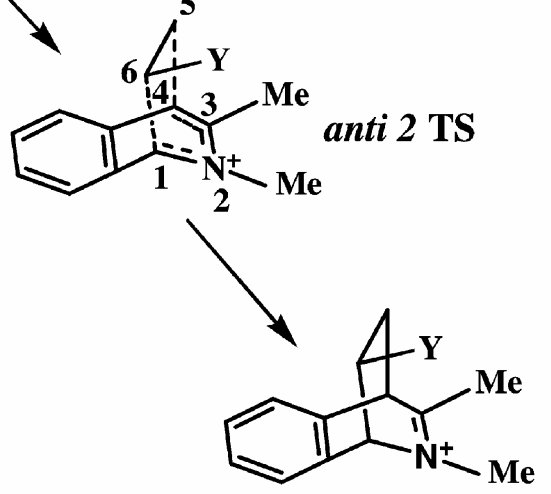

syn 2 TS

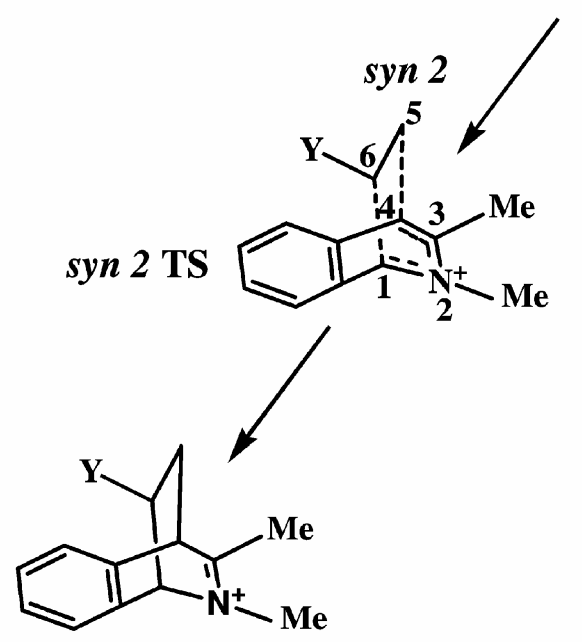

anti 2 TS

Scheme 2. Possible reaction pathways for the $\left[2+4^{+}\right]$reaction between MVE/PY and DMIQ.

usual measure to position the TS on the reaction path and locate them precisely. $\mathrm{BFC}_{\mathrm{Ave}}$ (table 2) reveals that the TSs are 'reactant' like and show that syn 2 TS is the most reactant-like. The regio and stereoselective formation of syn 2 isomer is also further supported by the stereoselective rule that says that the system tends to choose an orientation so as to have a maximum dipole moment ${ }^{21}$ and syn 2 TS has the highest dipole moment among all TSs and therefore is preferred.

$3.1 \mathrm{~b}$ Reaction between acridizinium ion and propylene: ACR undergoes $\left[2+4^{+}\right]$reaction with PY and there are two regiochemical paths (regio 1 and regio 2) possible and in each of them two stereo selective adducts (syn 1 and anti 1 and syn 2 and anti 2) could be formed. Calculated FOE gap (table 1) and $q_{c t}$ (figure 5) values show that the reaction is inverse electron demand type. The LUMO of ACR is C6$\mathrm{N} 5-\mathrm{C} 11-\mathrm{C} 12 \pi^{*}$ and therefore addition takes place across this unit. Computed free energy of activation and reaction (table 1) points out that the syn 2 is kinetically and thermodynamically the most favoured. Optimized asynchronous TSs shown in figure 5 and $\alpha$ values reveal that formation of $\mathrm{C} 14-\mathrm{C} 6$ bond is much faster than the $\mathrm{C} 13-\mathrm{C} 11$ and the most electron deficient carbon atom is $\mathrm{C} 6$ and the first attack takes place involve this carbon atom. The entropy loss is less for the syn 2 isomer than the other isomer. In addition to that, dipole moment values suggest that the syn 2 TS has maximum separation of charges and is the most stable and preferred one. ${ }^{21}$ This is in 

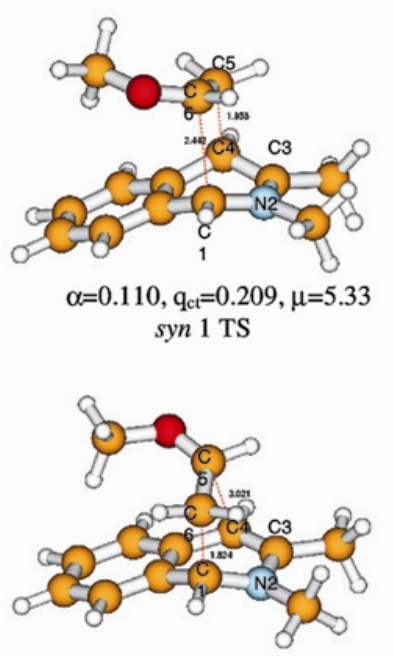

$\alpha=0.247, \mathrm{q}_{\mathrm{ct}}=0.197, \mu=5.95$ syn 2 TS
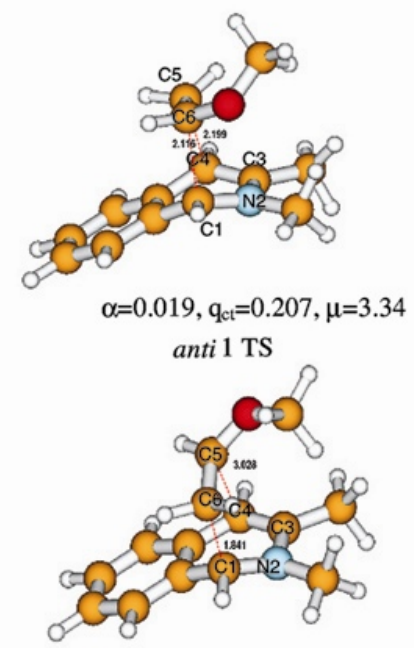

$\alpha=0.244, \mathrm{q}_{\mathrm{ct}}=0.186, \mu=3.50$ anti 2 TS

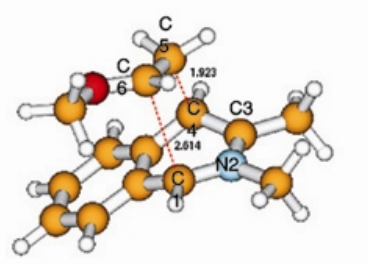

$\alpha=0.152, \mathrm{q}_{\mathrm{ct}}=0.388, \mu=5.98$ syn 1 TS

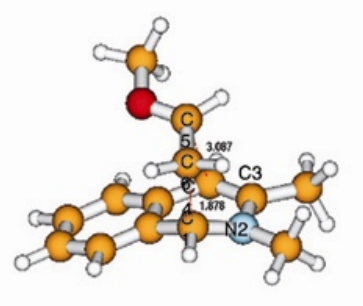

$\alpha=0.243, \mathrm{q}_{\mathrm{ct}}=0.176, \mu=5.91$ syn 2 TS

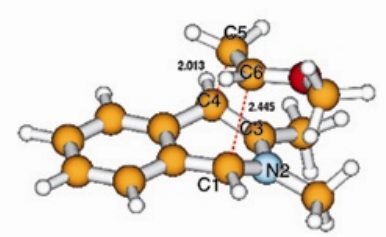

$\alpha=0.097, \mathrm{q}_{\mathrm{ct}}=0.240, \mu=3.46$ anti 1 TS

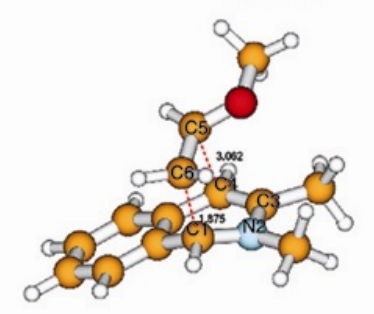

$\alpha=0.240, \mathrm{q}_{\mathrm{ct}}=0.335, \mu=3.47$

anti 2 TS

a) cis Orientation

Figure 6. Optimized transition state geometries for the $\left[2+4^{+}\right]$reaction between MVE (trans orientation) and DMIQ along with degree of asynchronicity $(\alpha)$, quantum of charge transfer $\left(q_{c t}\right)$ and dipole moment $(\mu)$.
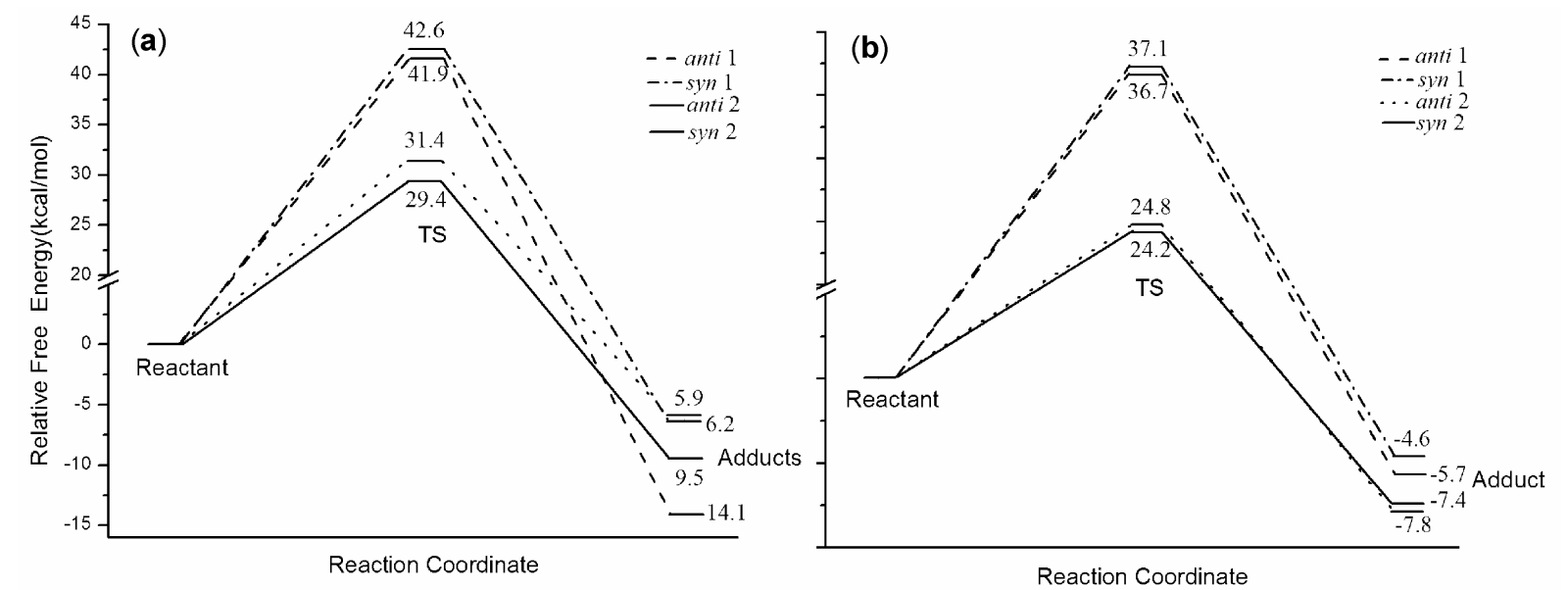

Figure 7. Free energy profile for the $\left[2+4^{+}\right]$reaction of DMIQ with MVE (a) cis orientation, (b) trans orientation.

agreement with the experimental report of Bradsher and coworkers. ${ }^{8}$ Calculations have been done for the ACR-Ethylene reaction to compare the reactivity trends and the dienophile reactivities follow the order MVE $>$ ET $>$ PY as revealed by free energy of activation and it could be understood from that the HOMO of these dienophiles are progressively stabilized in the same order. The trend obtained is well expected as these additions are HOMO dienophile controlled. Bond order analysis (table 2) shows that syn 2 TS is more reactant like.

\subsection{2,3-Dimethylisoquinolinium ion as a diene}

3.2a Reaction of 2,3-Dimethylisoquinolinium-methyl vinyl ether: DMIQ and MVE undergo inverse electron demand $\left[2+4^{+}\right]$addition through synchronous concerted mechanism and as explained earlier two regioselective modes are possible due to asymmetric nature of diene and dienophile, i.e. carbon bearing methoxyl group can react with either $\mathrm{C} 1$ or $\mathrm{C} 4$ atom of DMIQ and further in each of these additions the methoxy group can have syn or anti orientation rela- 

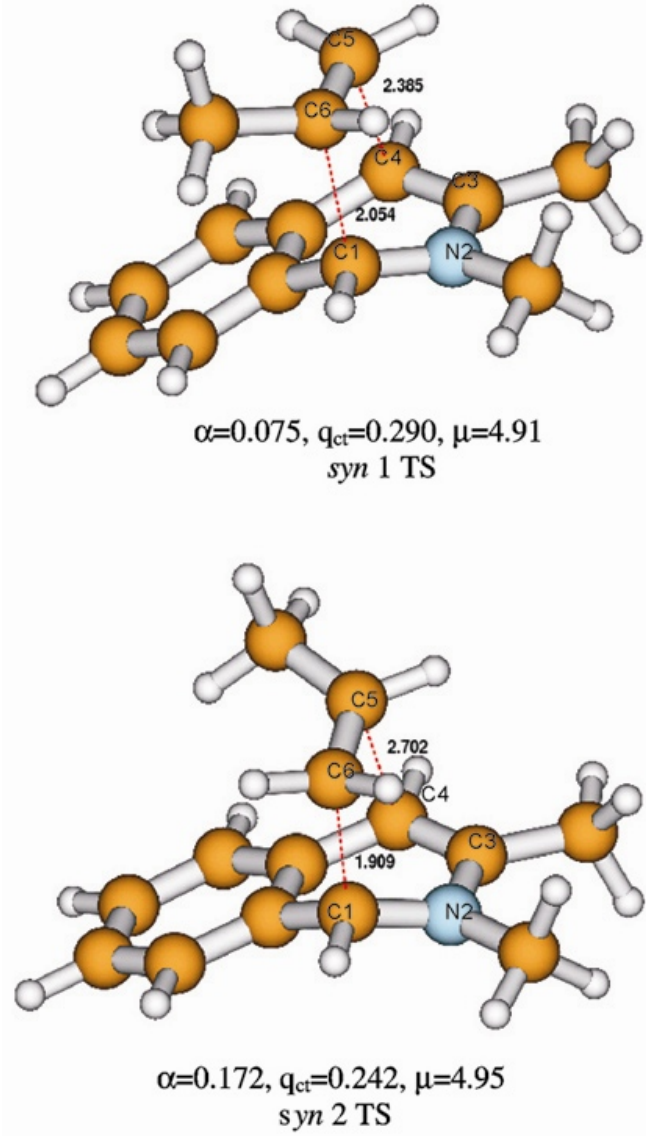
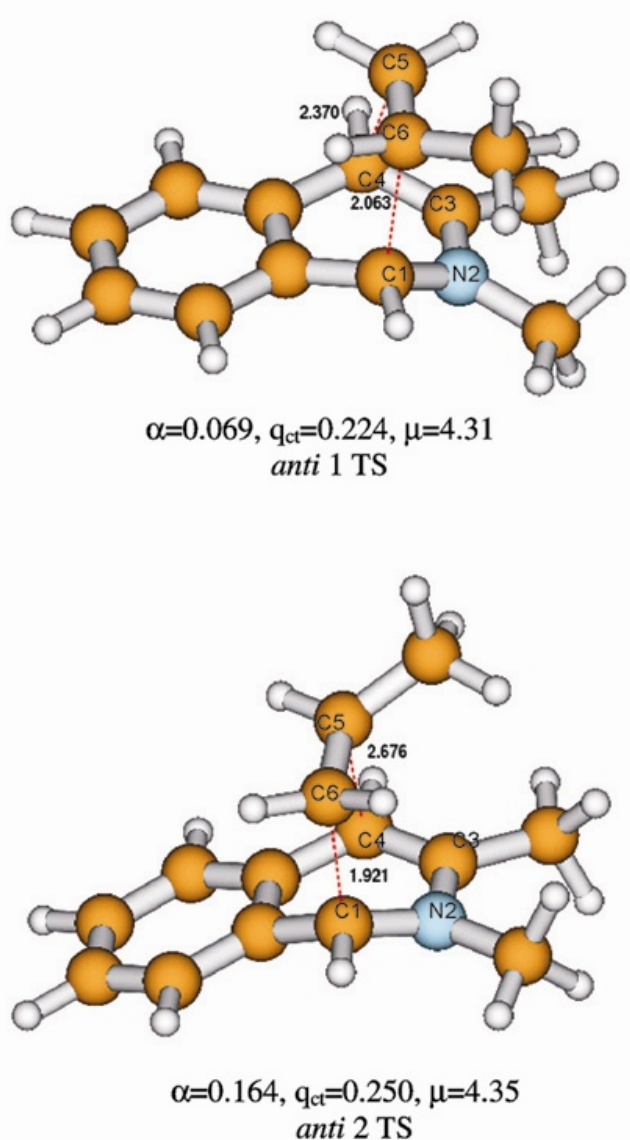

Figure 8. Optimized transition state geometries for the $\left[2+4^{+}\right]$reaction between PY and DMIQ along with degree of asynchronicity $(\alpha)$, quantum of charge transfer $\left(q_{c t}\right)$ and dipole moment $(\mu)$. tive to phenylene ring ultimately giving rise to four adducts (scheme 2). The four regio and stereo adducts are named as syn 1, anti 1, syn 2 and anti 2 and are shown in scheme 2. In the above adducts methoxyl group makes cis or trans orientation with respect to the double bond. FOE gaps given in table 3 confirm that the reaction is inverse electron demand type and is also well explained from the points of view of $q_{c t}$ values shown in figure 6. Further, LUMO of DMIQ fixes the reactive unit in DMIQ. Computed asynchronous TSs shown in figure 6 reveal that the bond $\mathrm{C} 1-$ C6 is formed much faster than the other bond C5$\mathrm{C} 4$ for the reason mentioned earlier. These reactions are also found to follow concerted mechanism with asynchronous transition states and step-wise paths could not be located. Free energy barriers ( given in table 3) for the addition with MVE with methoxy group having cis orientation to the reacting double bond are found to be higher, approximately by $4 \mathrm{kcal} / \mathrm{mol}$ than the trans orientation and thereby adducts with trans orientation is favoured. Free en- ergy profile of the regio and steroselective additions given figure 6 show that syn 1/anti 1 addition have high barrier $(6-10 \mathrm{kcal} / \mathrm{mol})$ compared to syn $2 /$ anti 2 addition and the enthalpy of activation also follows the same trend. Between anti 2 and syn 2 pathways, syn 2 adduct formation has the lower barrier. Therefore, among eight addition possibilities syn 2 addition is kinetically and thermodynamically more favoured which is in total agreement with experimental results. Bradsher and co-workers ${ }^{9}$ in their study on the reaction of MVE-DMIQ have isolated only one stereoisomer, which is syn 2. The high stereo selectivity has been proved by NMR and X-ray crystal structure studies. DMIQ-ET reaction was modelled for comparison and the activation free energy is found to be $35.3 \mathrm{kcal} / \mathrm{mol}$ which is $10 \mathrm{kcal} / \mathrm{mol}$ higher than that of DMIQ-MVE reaction. This is because the MVE is more electron rich than ethylene. From the values on the percentage of bond formation and cleavage in table 4 , the $\mathrm{BFC}_{\text {ave }}$ are found to be less than $50 \%$ and that shows 'early' nature of 
the TSs and in particular the syn 2 TS is the most reactant like. The IRC calculations provide that the geometry of the species that lie at 'halfway' between the TS and the cycloadducts (figure 3). These geometries that are located in a smooth drop in energy, after the barrier height show that $\mathrm{C} 6-\mathrm{Cl}$ bond is formed very fast about $1.72 \AA$. On the other hand, $\mathrm{C} 5-\mathrm{C} 4$ bond is much delayed and the distance is $2.95 \AA$. Moving the reacting system from the transition state towards the product side shows a gradual increase in the formation of $\mathrm{C} 5-\mathrm{C} 4$ bond and this confirms that the TSs obtained are indeed concerted asynchronous TSs and not step-wise TSs.

3.2b Reaction of 2,3-dimethylisoquinolinium-propylene: DFT Calculations have been performed for the reaction between DMIQ and PY and as described in scheme 2 four adducts (syn 1, anti 1, syn 2 and anti 2 ) are possible. Thermochemical activation parameters and FOE gap values are collected in table 3 and the free energy profile is drawn in figure 7. Optimized transition state geometries of the TSs are given figure 8 . Bond order analysis data for the reaction of ACR with PY are given in table 4. Computed FOE gap values reveal that the reaction is an inverse electron demand type. The whole potential energy surfaces have been scanned both for concerted and step-wise pathways but step-wise pathway was not found. Similar to the DMIQ-MVE reaction, activation free energy for the formation of the syn 2 TS is lower than that of all the other TSs. In this case also a syn 2 approach is found to be favourable. The values of degree of asynchronicity $\alpha$ confirm the asynchronous nature of the TSs. The reaction energies values show that this reaction is exothermic. The IRC calculations are found to connect the reactant and the corresponding products which show that concerted TS is on the right reaction path. $\mathrm{BFC}_{\mathrm{Ave}}$ values given in table 4 indicate that the above transition states are early transitions states. The free energies of activation of syn 2 adducts in reactions with MVE and PY show that between ACR and DMIQ the former is more reactive than the latter.

\section{Conclusions}

Cationic dienes ACR and DMIQ undergo regio and stereoselective $\left[2+4^{+}\right]$cycloadditions with methyl vinyl ether and propylene through concerted mechanism. Highly stabilized LUMO in both dienes are responsible for the inverse electron demand nature of the reaction as revealed by computed charges on the addends in the TS and FOE gap values. Asynchronous nature of the TSs confirm that it is a one step, two stage process involving the two forming bonds maturing at different rates. First formation of the bond between the most electron deficient carbon atom in the diene with the electron rich carbon in the dienophile reveals the dominance of electrostatic control in the initial phase of the reaction. The diene unit containing the $\mathrm{N}^{+}$in ACR and DMIQ form the LUMO and is highly reactive and this fixes the regioselectivity. Among the four possible stereoselective adducts syn 2 adduct is favoured in both ACR and DMIQ reaction and this is in agreement with the experimental observations. The regio and stereoselective formation of syn 2 isomer is also further supported by the stereo selective rule. The reactivity of the dienophiles employed here are in the order MVE $>$ ET $>$ PY and this is true with the progressive stabilization of HOMO in them. Between ACR and DMIQ the former is more electron deficient and is more reactive diene. Bond order analysis reveals that all the TSs are 'reactant' like. In these reactions though both electrostatic and frontier orbital control plays significant role, the former is dominant in the initial stage of the reaction.

\section{Acknowledgements}

Financial support from Council of Scientific and Industrial Research (CSIR), India through major research Grant No: 01(1649)/00/EMR-II is gratefully acknowledged. V T thanks the Swiss Federal Commission for their financial assistance.

\section{References}

1. Kavitha K and Venuvanalingam P 2005 Int. J. Quantum Chem. 10464

2. Boger D L and Weinreb S N 1987 (San Diego: Academic Press)

3. Bradsher C K and Solomons T W G $1958 \mathrm{~J}$. Am. Chem. Soc. 80933

4. Bradsher C K and Beavers L E $1955 \mathrm{~J}$. Am. Chem. Soc. 774812

5. Bradsher C K and Day F H 1971 Tetrahedron Lett. 5 409

6. (a) Bradsher C K and Stone J A 1969 J. Org. Chem. 34 1700; (b) Bradsher C K, Porter N A and Wallis T G 1974 J. Org. Soc. 39 1172; (c) Bradsher C K, Wallis T G, Westerman I J and Porter N A $1977 \mathrm{~J}$. Am. Chem. Soc. 992588 
7. Bradsher C K, Day F H, McPhail A T and Wong P S 1973 J. Chem. Soc. Chem. Comm. 5156

8. (a) Westerman I J and Bradsher C K $1979 \mathrm{~J}$. Org. Chem. 44 727; (b) Bradsher C K and Day F H 1973 J. Heterocycl. Chem. 10 1031; (c) Westerman I J and Bradsher C K 1978 J. Org. Chem. 433002

9. Fields D L, Regan T H and Dignan J C 1968 J. Org. Chem. 33390

10. Fields D L, Regan $\mathrm{T} \mathrm{H}$, Dignan J C, Burnham W S and Bradsher C K 1972 J. Org. Chem. 37 355

11. Tamilmani V, Claude Daul and Venuvanalingam $P$ 2005 Chem. Phys. Lett. 416354

12. Schlegel H B 1982 J. Comp. Chem. 3214

13. Gonzalez C and Schlegel H B 1990 J. Phys. Chem. 945523
14. Gonzalez C and Schlegel H B 1991 J. Chem. Phys. 955853

15. Frisch M J et al 2004 Gaussian, Inc, Wallingford CT, Gaussian 03, Revision C.02

16. Wiberg K 1968 Tetrahedron 241083

17. Manoharan M and Venuvanalingam P 1996 J. Chem. Soc. Perkin Trans. 21423

18. Manoharan M and Venuvanalingam P 1997 J. Chem. Soc. Perkin Trans. 21799

19. Manoharan M and Venuvanalingam P $1997 \mathrm{~J}$. Mol. Struct. (Theochem.) 39441

20. Asynchronicity $\alpha$ is calculated as $|a-b| /(a+b)$ where $a$ and $b$ are the newly forming bond lengths as cited in ref $[17,18]$

21. Domingo L R and Teresa Picher M 2004 Tetrahedron 605053 